\title{
Modelos agropecuários no oeste catarinense: dos povos tradicionais aos integrados das agroindústrias
}

\author{
Daniel Scheren da Cruz \\ Sacha Arielle Branco** \\ Ivo Dickmann ${ }^{* * *}$
}

Agricultural models in western of Santa Catarina-Brazil: from traditional people to integrated agroindustries

Palavras-chave:

Produção agropecuária

Caboclos

Descendentes europeus

Keywords:

Agricultural production

Caboclos

European descendants
Resumo:Noreferidoestudo oobjetivo central, será discorrer sobreo "desenvolvimento" do modelo de produção agropecuária da região Oeste do Estado de Santa Catarina. Sob efeito disto, torna-se necessário lançar a pesquisa, a qual foi realizada bibliograficamente, em direção ao povoamento ocorrido na região supracitada. Vão ser dados três enfoques ao povoamento e sua relação com os distintos modos de produção agropecuária. O primeiro enfoque será direcionado sobre os nativos desta terra, os quais já a povoavam muito antes da vinda dos europeus, e em seguida os caboclos, que eram de origem luso-brasileira. Por último a vinda dos descendentes de europeus com as suas técnicas de cultivo e formas de organização, assim como, a influência das empresas colonizadoras na divisão das terras. Outros dois pontos importantes são: o "desenvolvimento" do modelo agropecuário em nossa região sob a influência dos interesses do mercado neoliberal representado pela agroindústria, e as alternativas para a construção de um novo modelo agropecuário. Conclui-se que é possível estabelecer um novo modelo de produção na região de estudo, tendo em vista a diversidade de experiências que já fazem parte do histórico da economia solidária e da agroecologia no Oeste Catarinense.

Abstract: In this study, the central objective will be to discuss the "development" of the model of agricultural production in the Western Region of the State of Santa Catarina - Brazil. As a result, it is necessary to launch the research, which was carried out bibliographically, in the direction of the settlement occurring in the abovementioned region. Three approaches will be given to settlement and its relation to the different modes of agricultural production. The first approach will be directed at the natives of this land, who already inhabited it long before the arrival of the Europeans, and then the caboclos, who were of Portuguese-Brazilian origin. Finally the coming of the descendants of Europeans with their cultivation techniques and forms of organization, as well as the influence of colonizing companies in the division of land. Two other important points are the "development" of the agricultural model in our region under the influence of the interests of the neoliberal market represented by the agroindustry, and the alternatives for the construction of a new agricultural model. It is concluded that it is possible to establish a new production model in the region of study, considering the diversity of experiences that are already part of the history of solidarity economy and agroecology in the West of Santa Catarina - Brazil.

Recebido em 13 de outubro de 2017. Aprovado em 27 de dezembro de 2017.

\footnotetext{
* Mestrando no PPG Interdisciplinar em Ciências Humanas pela Universidade Federal da Fronteira Sul - UFFS. Licenciado em Ciências Sociais UFFS. E-mail: <danielscherendacruz@yahoo.com.br>.

** Graduanda em Ciências Biológicas na Unochapecó, atua como estagiária no Herbário da Unochapecó. E-mail: <sachabranco@unochapeco.edu.br>. *** Professor Titular do Programa de Pós-Graduação em Educação - Mestrado, Unochapecó. Pós-doutorando em educação (Uninove). Doutor em Educação pela Universidade Federal do Paraná (UFPR, 2011-2015). Mestre em Educação pela Universidade Federal do Paraná (UFPR, 2008-2010). Bacharel em Filosofia pelo Instituto Superior de Filosofia Berthier (IFIBE, 2005-2007). Aperfeiçoamento em Direitos Humanos (IFIBE). E-mail: <educador.ivo@unochapeco.edu.br>.
} 


\section{Introdução}

A proposta deste artigo é fazer um resgate histórico, através de pesquisa em fontes bibliográficas da região oeste catarinense, com o olhar voltado para as diversas práticas na agropecuária levando em consideração as três fases de ocupação: indígena, cabocla e de colonização (POLI, 1995).

Como o povoamento do oeste catarinense, no primeiro momento não se deu com a colonização dos descendentes de europeus, mas sim com os povos tradicionais. Discorreremos brevemente sobre o modo de produção de alimentos dos Kaingang e dos Guarani usando como principal fonte a obra de Noelli (1999-2000).

Antes de falar sobre os descendentes de europeus, apresentaremos as atividades agropecuárias desenvolvidas pelos caboclos, além de mostrar que assim como os povos tradicionais, as atividades praticadas por eles na agricultura fugiam dos parâmetros de normalidade do modo de produzir do capitalismo.

Posterior a estas duas abordagens sobre os modelos de produção agropecuária, do indígena e do caboclo, é que entraremos na questão referente à colonização branca e sua maneira de fazer agropecuária tentando observar na história, e na divisão dos lotes de terras pelas companhias colonizadoras, as causas da atual organização fundiária na região, assim como o surgimento e o desenvolvimento das agroindústrias, algumas disfarçadas como cooperativas (DICKMANN; DICKMANN, 2015).

Através de uma concepção teórica eideológica mostraremos dois rumos possíveis de serem seguidos. Um é voltado à concentração da produção e que interessa ao agronegócio, ao capitalismo. O outro rumo é como uma resposta às consequências geradas pelo atual modelo de produção e se orienta na agroecologia e na economia solidária.

\section{Modelo agropecuário dos povos tradicionais}

Como faremos uma abordagem histórica sobre os modelos agropecuários da região, nada mais justo do que iniciar pelos povos que são os verdadeiros pioneiros do oeste catarinense, os indígenas. Ao mesmo tempo esta abordagem também servirá para desmistificar a visão que as pessoas geralmente possuem sobre os índios, rotulando-os como preguiçosos que vivem somente da caça, da pesca e da coleta.

Essa visão de que os índios são preguiçosos, pode facilmente ser desmentida pelo trabalho antropológico feito por Pierre Clasters (1988). Nesta obra ele mostra que os povos chamados de primitivos não desenvolvem o Estado, pois no meio de sua convivência social não existem dispositivos para tal. Ao argumentar sobre isso, ele discorre desde a economia até a figura do chefe das sociedades primitivas, porém, o que nos interessa aqui é a questão da economia referente ao trabalho.

Segundo Clasters (1988), os indígenas trabalhavam muito pouco por dia, o suficiente para terem o que comer. Isso mostra que eles tinham uma economia de subsistência, que leva algumas pessoas a pensarem que esses povos trabalhavam o dia inteiro para apenas sobreviver como animais. Aí elas entram em contradição, ou são preguiçosos ou trabalham o dia inteiro, e se trabalhavam o dia inteiro, então, não são preguiçosos. Na verdade, Clasters mostra que eles não trabalhavam mais, pois não necessitavam, e o pouco que trabalhavam, além de ser suficiente para o sustento de todos na aldeia, produzia um pouco de excedente que não era comercializado, mas sim usado para celebrações, visita de estrangeiros ou em períodos de escassez.

Dentre os grupos tradicionais que habitaram o oeste iremos nos restringir aos Kaingang e aos Guarani, pois foram essas culturas indígenas que além de terem desenvolvido práticas agrícolas, tiveram maior relevância, se assim podemos dizer, no povoamento da região.

\section{Povo Kaingang}

Segundo Noelli (1999-2000) os Kaingang, a exemplo dos Xokleng, são descendentes da matriz cultural Macro-Jê e oriundos da atual região centrooeste do Brasil. 
Tinham pelo menos quatro formas de assentamento, eram eles: abrigo, céu aberto, sambaquis e casas subterrâneas.

Os ditos homens brancos se utilizaram de um falso nomadismo tradicional dos Kaingang como justificativa para requererem as terras. Porém, este nomadismo se deu a partir de pressões do povo Guarani e posteriormente dos próprios brancos. Um exemplo disto é a mudança ocorrida na sua cultura material. Com a constante investida dos colonizadores eles largaram o hábito de construir casas subterrâneas, o que pode ser constatado em estudos arqueológicos, pois tinham que migrar constantemente. Ou seja, o nomadismo não era tradicional, mas sim forçado.

Outra evidência sobre o seu falso nomadismo tradicional é a de que, além de eles obterem os seus alimentos através da caça, da pesca e da coleta, também desenvolveram a agricultura "[...] desenvolviam tecnologias típicas de cultivo em clareiras na floresta e em outros lugares [...]" (NOELLI, 1999-2000, p. 247) desenvolvendo, também, o manejo agroflorestal com as araucárias de onde extraiam o pinhão, um dos principais componentes de sua dieta alimentar (BITENCOURT; KRAUSPENHAR, 2006; IRIARTE; BEHLING, 2007).

$\mathrm{Na}$ agricultura Kaingang se cultivava principalmente a mandioca, a batata doce, a batata "inglesa", o cará, o milho, o feijão e o amendoim.

\section{Os Guarani}

Os Guarani são descendentes da matriz cultural Tupi-Guarani da região amazônica. Este povo chegou até nossa região através de uma migração que durou centenas de anos, porém, eles não eram nômades, pelo contrário, tinham certa predisposição sedentária, tanto que esta migração acontecia somente quando as aldeias aumentavam o seu contingente populacional se tornando necessária a saída de alguns membros para fundar uma aldeia nova em outro lugar.

A migração relatada no parágrafo acima evidencia pelo menos dois fatos a se refletir: 1) $\mathrm{O}$ perfil guerreiro dos Guarani, evidenciado pela migração da região amazônica até a região oeste catarinense, ocupando vários outros lugares pelo caminho, os quais já eram habitados tendo que conquistá-los para poder povoá-los; 2) O fato de encontrar-se algumas plantas oriundas da Amazônia em outras regiões habitadas pelo povo Guarani, pois eles levavam consigo uma espécie de "kit" com plantas diversas (SCHMITZ; FERRASO, 2011; MILHEIRA, 2010).

Esta última reflexão evidencia que os Guarani faziam certo manejo agroflorestal, o qual Noelli (1999-2000, p. 249) apresenta da seguinte maneira:

Seu sistema de manejo agroflorestal certamente contribuiu para a ampliação da biodiversidade das comunidades vegetais das regiões onde se instalavam, uma vez que em vários pontos do Sul do Brasil há espécies nativas de outras regiões, como a própria Amazônia, Centro-Oeste do Brasil, Chaco, Andes e Pampa. O manejo era feito no interior de cada teko á, o território de domínio de cada assentamento, entrecortado por trilhas que interligavam as aldeias e estas às roças, áreas de coleta, pesqueiros, áreas de caça etc. Uma vez que as aldeias formavam conjuntos unidos politicamente por meio de alianças regionais, além dos laços de parentesco, havia um sistema de troca de mudas e sementes como ocorre entre vários com o mesmo tipo de sistema agroflorestal, garantindo a disseminação de espécies entre os teko`á..

Esta citação deixa claro que assim como os Kaingang, os Guarani também eram agricultores tendo a caça, a coleta e a pesca apenas como uma atividade complementar. $\mathrm{O}$ modo de cultivar e a organização das roças dos Guarani, demonstra que eles cultivavam em diversos locais, considerando as taxas variáveis de clima, umidade, tipos de solo, etc. Além da roça instalada em clareiras nas matas, plantavam: 1) junto às casas, dentro do perímetro da aldeia, formando pomares, hortas medicinais e de plantas para matéria-prima; 2) trilhas que ligam aldeias e roças entre si; 3 ) pequenas clareiras ao lado das trilhas; 4) locais onde encontravam clareiras naturais ou onde derrubavam árvores para coleta de madeira, mel ou insetos; 5) micronichos 
especiais; 6) criavam e ampliavam comunidades de uma espécie predominante, como os ervais de mate (Ilex), palmitais (Euterpe), pinheirais (Araucaria), entre várias outras (NOELLI, 1999-2000, p. 249-254).

As principais culturas cultivadas pelos Guarani eram: mandioca, batata doce, batata "inglesa", cará, mangarito, araruta, batatinha, milho, feijão, amaranto, quina, amendoim, feijão guandu, fava de rama e lágrima de nossa senhora. É importante ressaltar também que estes povos preferiam habitar terras nas proximidades de grandes rios, no nosso caso os rios Uruguai e Iguaçu e a foz do rio Chapecó.

\section{Modelo agropecuário dos caboclos}

Primeiramente é importante situar de quem estamos falando e para isso utilizamos uma passagem de Poli (1995, p. 100) que diz: "Basicamente, pois, o caboclo é conceituado como luso-brasileiro, e sua condição fundamental de reconhecimento é ser pobre e viver toscamente.." Ou seja, além da questão étnica de miscigenação entre portugueses e índios ou africanos, o caboclo também pode ser rotulado pela sua situação econômica, visto que ao conseguirem melhorar de vida já não eram chamados mais de caboclos.

A cultura dos caboclos, embora seja muitas vezes esquecida, é muito rica, e na maneira de manejar os recursos naturais e desenvolver suas práticas agropecuárias não é diferente. Tinham em sua base alimentar produtos provenientes de suas roças, da caça, dentre outros.

Embora, por demasiado, ocultado na história da região, o caboclo desempenhou um papel fundamental para o desenvolvimento do oeste catarinense. $\mathrm{O}$ caboclo participou de várias atividades econômicas que antecederam a estrutura atual, sempre com o trabalho mais pesado. Estava presente nas tropas, na extração de erva-mate e no período das balsas.

\section{Alguns hábitos caboclos na lida com a terra}

Segundo o Centro de Memória do Oeste de Santa Catarina - CEOM, os caboclos dividiam as terras em terras de criar e terras de plantar. As terras de criar geralmente ficavam próximas da residência e tinham uma área com água e sombra das árvores abundantes para usufruto dos animais. Os porcos, por exemplo, eram criados em "[...] mangueirões de duas quartas. A base da alimentação eram frutos silvestres e também abóbora, batata doce, milho e mandioca. No inverno os porcos eram conduzidos para os pinheirais devido à abundância de pinhões." (CEOM, 2008, p. 29).

Já as terras de plantar ficavam mais longe das de criar, motivo pelo qual os animais criados soltos não danificavam a lavoura. Nessas áreas os caboclos utilizavam o "[...] fogo, para o desmatamento, que também tinha função fertilizante [cinzas] e limitadora do desenvolvimento de ervas daninhas." (WOLOSZYN, 2005). As terras de plantar eram utilizadas uma ou duas vezes e em seguida se utilizavam de uma nova área enquanto a primeira ficava em repouso. "Essa técnica agrícola de derrubada e queimada, denominada, também, de 'coivara', era praticada tradicionalmente pelas populações horticultoras tupi-guarani, de quem os caboclos tomaram de empréstimo." (WOLOSZYN, 2005).

As culturas mais cultivadas pelos caboclos eram o amendoim, a abóbora, o arroz, a banana, o feijão, a melancia, a mandioca e o milho, além do manejo da erva-mate. Alguns desses produtos eram trocados em estabelecimentos comerciais, bodegas, "[...] por sal, bebidas, querosene, pólvora, instrumentos de trabalho etc." (WOLOSZYN, 2005).

Para trabalhar a terra eram usados instrumentos como o xaxo, a foice, o machado e a enxada. $\mathrm{O}$ xaxo era o mais usado e consistia em um "[...] pedaço de metal preso numa madeira cilíndrica, que servia para fazer as covas, nas quais eram depositadas as sementes." (CEOM, 2008, p. 21).

\section{Modelo agropecuário dos colonizadores}

Ao falar sobre os colonizadores do oeste catarinense, neste caso, estamos falando de descendentes de alemães, italianos, poloneses, dentre outros povos europeus, oriundos das colônias do Rio Grande do Sul. 
Esta colonização gerou muitos conflitos e impasses pelo motivo de existir nessas terras outras pessoas que já a cultivavam e nela residiam. Eram os caboclos e alguns grupos indígenas.

O processo de colonização se deu a partir de um interesse do governo do estado de ocupar a área e desenvolvê-la. Isso ocorreu com o próprio governo dando a concessão de terras, chamadas devolutas, para algumas empresas colonizadoras.

Um aspecto importante, e que aparecerá em outro momento neste artigo, é a mentalidade dos descendentes europeus, que divergia da mentalidade dos caboclos e dos povos tradicionais. Esta forma de pensar e se organizar do homem branco foi fundamental para estruturar a economia atual da região.

Woloszyn (2005) retrata da seguinte maneira a relação dos primeiros colonizadores com o novo habitat:

Para fazer as roças, cortavam-se as árvores maiores com o machado, e as menores, assim como o capim, com foice. Queimavam a mata derrubada e o terreno estava pronto para plantar. Cultivava-se arroz, batata, feijão, mandioca, milho, trigo e outros produtos, que serviam como alimento básico para a família. O excedente era comercializado. Destaque-se que, por determinações geoecológicas profundas, os métodos produtivos e os gêneros plantados pelos colonos pioneiros eram muito parecidos aos dos caboclos, dos quais haviam sido em boa parte, adquiridos. Além da atividade agrícola, destacou-se também a pecuária - especialmente bovina e suína, ainda que, em geral, insuficiente para uma rica adubação dos terrenos.

Dentro deste processo de desenvolvimento de um novo modelo agropecuário acreditamos ser importante compreender algumas coisas como a distribuição das terras pelas colonizadoras, o surgimento das agroindústrias, dentre outros fatores os quais serão abordados na sequência deste artigo.

\section{Transição de modelo agropecuário através de uma concepção ideológica}

Elencamos um subitem para falar especialmente sobre isso, pois consideramos importante para a compreensão da crítica que faremos no final do trabalho.

O modo de produzir alimentos dos povos tradicionais, como vimos acima sob a luz de Pierre Clasters (1988), é pautado em uma cultura de subsistência onde produzem para sua aldeia e não visam excedentes, até porque não existe essa necessidade, sendo que eles não possuem mercados para comercializá-los tendo em vista o lucro. Ou seja, possuíam uma lógica de organização produtiva distinta do europeu.

O modelo caboclo, assim como o indígena, também era de subsistência não tendo a ideia de lucro e acumulação de riqueza.

Já a mentalidade dos descendentes europeus está embasada em uma cosmovisão liberal. Para Guareschi (2004), uma cosmovisão abrange pelo menos quatro dimensões, são elas: visões de ser humano; filosofia (valores); tipo de sociedade; e comportamentos, relações. O que nos interessa no momento é a dimensão referente ao tipo de sociedade que no caso da cosmovisão liberal é a sociedade capitalista, mesmo sabendo que todas elas estão articuladas dialeticamente.

O capitalismo é o modo de produção no qual nossa sociedade está estruturada. É também o contexto no qual viviam os primeiros colonos europeus antes de chegarem ao Brasil, nas colônias do Rio Grande do Sul. Com isto, mesmo que inconsciente, os descendentes europeus que colonizaram o oeste catarinense também desenvolveram essa mentalidade, pois acreditamos que um sujeito é constituído como tal por causa do meio cultural no qual ele foi criado.

Aí é que se encontra, a nosso ver, o ponto de transição, no campo ideológico, de um modelo agrário de subsistência para um de acumulação. Porém, outros fatores somados a este contribuíram para esta transição, dentre eles: as companhias colonizadoras e a divisão de terras; os clubes 4-S; revolução verde; e as agroindústrias. 


\section{Influência das colonizadoras nas divisões de terras: minifúndio e agricultura familiar}

A ação das colonizadoras no oeste catarinense foi uma tentativa de expansão do capitalismo, pois a colonização se deu a partir de grupos de empresários interessados em lucrar com a venda das madeiras e das terras. Várias foram as colonizadoras que atuaram na região, algumas pegando extensões de terra diretamente com o governo de Santa Catarina e outras indiretamente através da Brazil Development e Colonization, empresa ligada a Brazil Railway, e que obteve um bom lucro neste processo (WERLANG, 1995, p. 10).

$\mathrm{O}$ governo catarinense desejava a implantação de "[...] pequena e média propriedade, dependendo da atividade a que se destinasse [...]", sendo que a grande maioria das terras foram demarcadas em pequenas propriedades com lotes de 20 a 35 hectares, e a "[...] adoção dessa política deu-se em função do relevo acidentado, coberto de mata, que não interessava ao latifundiário." (WERLANG, 1995, p. 11).

A Cia. Sul Brasil foi umas das principais a demarcar as terras tendo em vista as pequenas propriedades. Isto ocorreu muito em fato, também, de Carlos Culmey, diretor-gerente da colonizadora, ter certa aversão aos latifundiários. Werlang (1995, p. 15) relata que: "Para ele não interessavam os lucros imediatos, os quais [...] só seriam possíveis com a implantação de latifúndios do qual se dizia inimigo." O fato provocou divergências entre Culmey e os empresários da Companhia pois estes queriam lucros imediatos a partir da simples venda das terras.

A divisão de terras no oeste de Santa Catarina da forma que ocorreu proporcionando com que aqui tivesse uma estrutura minifundista, ocasionou o desenvolvimento da agricultura familiar que posteriormente foi integrada a agroindústria. (SILVESTRO, 1995; PLEIN, 2005; PERTILE, 2011).

\section{Influência dos Clubes 4-S e a Implantação do Pacote da Revolução Verde}

Os clubes 4-S (saber, sentir, saúde e servir) no Brasil tem origem nos clubes 4-H dos Estados Unidos e foi implantado em nosso estado "[...] pela ACARESC (Associação de Crédito e Extensão Rural de Santa Catarina), órgão responsável pela implantação e desenvolvimento da Extensão Rural no estado [...]" e tendo em vista a "[...] preocupação com a constituição de um novo jovem rural em Santa Catarina." (SILVA, 2011, p. 38). Como os agricultores de certa forma tinham receio em aderir os novos métodos, a solução encontrada foi fazer com que eles experienciassem por si mesmos, através do clube 4-S, os resultados do trabalho desenvolvido na tentativa de mostrar que eles teriam maior rentabilidade.

Para Silva (2011, p. 44), os clubes 4-S na região serviram para contrapor o modelo praticado até então:

Os conhecimentos agrícolas
tradicionais, voltados principalmente
para práticas de agricultura extensiva
(agricultura itinerante, pautada
principalmente nas queimadas) e de
subsistência, foram deslegitimados
sistematicamente, enquanto os insumos
considerados modernos, científicos,
foram gradualmente inseridos no
cotidiano dos produtores rurais.

Desta maneira os clubes 4-S também serviram como válvula de escape para o pacote verde originário da Revolução Verde que consistia na comercialização dos restos químicos provenientes da Segunda Guerra Mundial.

Porém, sabe-se que estes insumos químicos, como os agrotóxicos, podem causar complicações na saúde humana, além de poluírem o solo e a água, e que os adubos químicos em longo prazo podem danificar o solo e incapacitar a sua produtividade (FERNANDES; STUANI, 2015). 


\section{Avanço capitalista através das agroindústrias}

Devido vários fatores, o oeste catarinense se tornou umlugar propício para o avanço dos interesses neoliberais representados pela agroindústria e/ ou agronegócio. Já foi citado acima a concepção ideológica dos colonizadores, o minifúndio com uma agricultura familiar articulada e a influência dos clubes 4-S na forma de produzir introduzindo insumos oriundos da Revolução Verde.

Por exemplo, o seguinte trecho pode ser usado para relacionar a atuação dos clubes 4-S e as agroindústrias:

No início da década de 1970, o êxodo rural atende aos interesses do desenvolvimentismo, da agroindústria, com a industrialização e urbanização. $\mathrm{O}$ que fundamenta as práticas governamentais neste período é que alguns jovens permaneçam no campo, $\mathrm{o}$ suficiente para realizar atividades como dirigir tratores, pulverizar as plantações de sementes híbridas com agrotóxicos e criar animais selecionados para as agroindústrias. (SILVA, 2011, p. 45).

Segundo Alves e Mattei (2006, p. 14), a relação existente entre os agricultores e as agroindústrias se dá em um sistema de integração no qual a Sadia Concórdia é pioneira. Estes autores apresentam a estrutura de relação entre as partes envolvidas na integração como sendo:

[...] comparada às modernas organizações flexíveis, em que a planta principal transfere para os demais elos da cadeia os principais riscos envolvidos no processo produtivo, bem como uma importante soma de encargos sociais e trabalhistas. Porém, centralizando os elos que envolvem maior agregação de valor, destacando-se o processamento industrial e a comercialização. (ALVES; MATTEI, 2006, p. 14).

O setor agroindustrial no oeste passou por várias etapas até que por volta do início da década de 1980 começou a ser reestruturado. Com isso, o ciclo completo de produção foi descentralizado.
Por exemplo, se antes um produtor tinha em sua propriedade o ciclo completo, com a reestruturação passa a ter somente uma parte do ciclo, enquanto outro produtor abriga outra parte do ciclo. Por exemplo: Lactação e terminação no caso da suinocultura; a produção de matrizes e o processo de engorda no caso do frango na avicultura.

\section{Conjuntura atual}

No contexto atual, observam-se alguns acontecimentos que podem acarretar um aprofundamento da tendência neoliberal nos campos oestinos, o que teoricamente seria ruim para os camponeses e as pequenas propriedades rurais. Dentre essas possibilidades que se apresentam no horizonte das transformações do trabalho rural, está a tentativa progressiva de ampliação da produção agrícola em larga escala de concentrar setores como a suinocultura, a avicultura e a bovinocultura de leite, em grandes propriedades rurais - que caso se efetive, vai prejudicar os camponeses.

Esta concentração tem a tendência de ocorrer gradativamente através dos anos e acontece graças a uma política de financiamentos, na qual o agricultor é praticamente forçado a aderir, caso contrário, não acompanhando as exigências não poderá vender o fruto de seu trabalho. Além disso, fica cada vez mais amarrado à empresa na qual está integrado.

Outro fator contributivo e que leva o agricultor a fazer financiamentos, e até mesmo excluí-lo do mercado, pode ser encontrado em uma passagem do trabalho de Alves e Mattei (2006, p. 15), que diz: "A necessidade de aumentar as escalas produtivas para atender as especificações das empresas integradoras também pode ser caracterizada como uma forma de excluir alguns estabelecimentos menos capitalizados do processo produtivo".

Este afunilamento na produção agrária contribui para os interesses da agroindústria, pois assim esta conseguiria pagar um valor razoável para quem produz e teria um crescimento considerável na quantia de mão de obra barata na cidade, para os seus frigoríficos, resultante do êxodo 
rural (SILVESTRO, 2001; SPANEVELLO, 2008; STROPASSOLAS, 2011).

Isto pode ser explicado pela Teoria da Localização da Indústria do economista Alfred Weber. Este propõe a redução dos custos da indústria a partir de sua localização relacionada às questões relativas a transporte, distância das matérias-primas e mercado consumidor, a oferta de mão de obra, e as aglomerações. Segundo Kusbick e Tartas (2015), esta teoria contribui para entendermos a implantação e desenvolvimento da agroindústria na região oeste catarinense, visto que os agricultores familiares e camponeses dessa região são considerados mão de obra qualificada para esse trabalho específico, tanto na propriedade rural como na agroindústria - quando do êxodo para as periferias das cidades da região.

O mesmo exemplo pode ser utilizado na produção da suinocultura no estado de Goiás. Os custos com o transporte dos grãos, dos suínos e do produto final ao mercado consumidor, entre outros fatores, apontam o estado supracitado como um ótimo local para a instalação das abatedoras de suínos. Este mesmo contexto apresenta-se no oeste catarinense evidenciando o debate realizado neste artigo (KUSBICK; TARTAS, 2015; LOPES; CAIXETA FILHO, 2000).

O contexto de produção da avicultura também pode ser observado em nossa região. Os diversos fatores estudados pela Teoria da Localização da Indústria que foram aplicados na produção da suinocultura, no parágrafo anterior, também podem ser aplicados na avicultura. Os fluxos migratórios e o aumento populacional, os investimentos públicos, e as políticas de proteção e incentivo à agroindústria, e o processo de acumulação, permitiram que Chapecó se colocasse como referência de uma região que possui empresas presentes entre as maiores produtoras $\mathrm{e}$ exportadoras de carne de ave (KUSBICK; TARTAS, 2015; RECHE; SUGAI, 2008).

Esse cenário favorável de mão de obra e trabalho, logística e transporte, não considera os impactos socioambientais relativos a esse modelo, especialmente no que tange a falta de qualidade de vida dos empregados das agroindústrias (tanto no campo como na cidade), a partir de baixas remunerações por um trabalho constante, sem folgas, feriados, devido à necessidade diária de alimentação dos animais. Outro aspecto a considerar é a acumulação do capital resultado desse trabalho nas mãos dos acionistas das agroindústrias privadas (gerador de grandes fortunas) e da dificuldade das agroindústrias cooperativas de distribuir as sobras entre os agricultores cooperados (o que destoa dos grandes salários pagos à direção das cooperativas e federações, entre outros benefícios).

\section{Considerações Finais}

Até aqui já foram apresentados os três levantes distintos do povoamento da região oeste catarinense e seus respectivos modelos agrários, sendo o modo de produzir dos povos tradicionais e dos caboclos pautados em uma agropecuária de subsistência e o dos descendentes de europeus, o que tinha em vista a produção de um número considerável de excedentes para posterior comercialização e obtenção de lucros.

Analisando ambos os modelos, pode-se perceber que é equivocado dizer que o jeito de produzir dos povos tradicionais e dos caboclos não causavam impactos na natureza, porém, o modo dos colonizadores de lidar com a terra, principalmente com o avanço do agronegócio, resulta em muito mais danos ao meio ambiente e de maneira mais acentuada: os agrotóxicos, a monocultura extensiva, o desmatamento e a desertificação (PESSOA; RIGOTTO, 2012; FIRMINO; FONSECA, 2008).

Podemos citar como alguns exemplos de deterioração dos recursos naturais, a prática usada pelos primeiros colonizadores de arar a terra, a utilização intensiva de insumos químicos para a lavoura, o código florestal vigente, entre alguns outros.

A técnica de arar trazida para o Brasil pelos descendentes europeus foi um fator que contribuiu para o empobrecimento do solo de nossa região. Era bastante usada, pois, tinha-se a ideia de que afofava a terra e a preparava para o plantio, contudo, esta prática era comum no continente europeu no inverno sendo utilizada para remover 
o gelo que pairava em cima da terra a ser cultivada (NICOLODI, 2007).

O empobrecimento do solo se dá porque o arado, ao movê-la, traz os micro-organismos anaeróbicos responsáveis pelo desenvolvimento da planta para a superfície e soterra os microrganismos aeróbicos, os quais também contribuem para o crescimento da planta. Assim, ambos os micro-organismos morrem, e como eles é que desempenham o papel de levar até as plantas os nutrientes como o nitrogênio, o solo fica com um baixo nível de produtividade.

Falando um pouco sobre os insumos químicos destacamos o adubo químico e os agrotóxicos. A adubação química, assim como a orgânica e a verde, é utilizada com o intuito de repor nutrientes na terra que em alguns casos estão em falta por decorrência do manejo inadequado do solo como quando na utilização do arado, como citado acima.

Em curto prazo, a utilização da adubação química até pode dar certo, todavia, a consequência decorrente de seu uso em longo prazo vai acarretar uma infertilização do solo, que se não diagnosticada de imediato, se torna irreversível, iniciando um processo de desertificação.

Os agrotóxicos são utilizados com o objetivo de eliminar as pragas e as doenças que assolam as culturas na lavoura. Entretanto, a sua aplicação resulta em vários malefícios para a natureza. Polui o solo que germina a semente que servirá de alimento, polui a água que ingerimos e, consequentemente, intoxica o nosso organismo, sendo um dos atuais, e principais, causadores de câncer (GASPARINI; VIEIRA, 2010).

Para mudar todo este quadro é preciso trocar as relações que dão base para ele. Com isso, toda a estrutura mudaria. Outro caminho que consideramos provável, devido a atual conjuntura, é a criação de dispositivos que venham a contribuir para a ruptura com o grande capital, como a agroecologia, os empreendimentos da economia solidária e consumo local na perspectiva do comércio justo.

Uma produção agroecológica que não causa danos ao meio ambiente, saudável e organizada em uma economia solidária, a qual possibilita o agricultor ser dono da riqueza que ele produz e atendendo as demandas do consumo local é, a nosso ver, uma boa alternativa para que os agricultores da região oeste de Santa Catarina possam romper com o agronegócio e seu modelo de agricultura convencional trazendo dignidade para a vida no campo e contribuindo para a diminuição do êxodo rural.

Neste sentido, na conjuntura atual, poderse-ia buscar nos saberes tradicionais indígenas, especialmente no que se refere ao modo de produção de subsistência, subsídios para um modelo de práticas agroecológicas e de economia baseada na solidariedade, bem como nas práticas dos caboclos que tinham uma relação sustentável com a terra. Embora não se negue que os colonizadores acoplaram aqui um modelo capitalista de gestão de propriedade, oriundo de seus antecedentes europeus, a divisão em pequenos lotes têm o potencial de criar um dispositivo contra hegemônico de produção na perspectiva da economia solidária.

Portanto, isto demonstra que a economia solidária e a agroecologia apresentam-se como alternativa ao modelo agroindustrial integrador, colocando-se como uma possibilidade concreta de modo de vida e de produção.

\section{Referências}

ALVES, P. A.; MATTEI, L. F. Migrações no oeste catarinense: história e elementos explicativos. XV Encontro Nacional de Estudos Populacionais, Caxambu-MG, 18-22 de setembro, 2006. Disponível em: <http://www.abep.nepo.unicamp. br/encontro2006/docspdf/ABEP2006_598.pdf>. Acesso em: 30 nov. 2016.

BITENCOURT, A. L. V.; KRAUSPENHAR, P. M. Possible prehistoric anthropogenic effect on Araucaria angustifolia (Bert.) O. Kuntze expansion during the late Holocene. Revista Brasileira de Paleontologia, v. 9, n. 1, p. 109-116, 2006.

CENTRO DE MEMÓRIA DO OESTE DE SANTA CATARINA. Inventário da cultura imaterial 
cabocla no oeste de Santa Catarina. Chapecó: Argos, 2008.

CLASTERS, P. A sociedade contra o Estado. Rio de Janeiro: Francisco Alves, 1988.

DICKMANN, I.; DICKMANN, I. Cooperativa habitacional autogestionária: construindo alternativas coletivas. In: DICKMANN, Ivo; DICKMANN, Ivanio (Orgs.). A questão da habitação popular. Curitiba: Base Editorial; IBEP, 2015. p. 175-190.

FERNANDES, C. S.; STUANI, G. M. Agrotóxicos no ensino de Ciências: uma pesquisa na Educação do Campo. Educação e Realidade, Porto Alegre, v. 40, n. 3, p. 745-762, jul./set. 2015.

FIRMINO, R, G.; FONSECA, M. B.; Uma discussão sobre os impactos ambientais causados pela expansão da agricultura: a produção de biocombustíveis no Brasil. IV ENAMPPAS, Brasília, junho de 2008. Disponível em: <http://www.anppas. org.br/encontro4/cd/ARQUIVOS/GT4-795-67520080510155652.pdf>. Acesso em: 30 nov. 2016

GASPARINI, M, F.; VIEIRA, P, F. A (in)visibilidade social da poluição por agrotóxicos nas práticas de rizicultura irrigada: síntese de um estudo de percepção de risco em comunidades sediadas na zona costeira de Santa Catarina. Revista de Desenvolvimento e Meio Ambiente, n. 21, p. 115127, jan./jun. 2010.

GUARESCHI, P. A. Sociologia Crítica: alternativas de mudança. 55 ed. Porto Alegre: EDIPUCRS, 2004.

IRIARTE, J.; BEHLING, H. The expansion of Araucaria Forest in the southern Brazilian highlands during the last 4000 years and its implications of the Taquara/Itararé Tradition. Environmental Archaeology, v. 12, n. 2, p. 115-127, 2007.

KUSBICK, F. A.; TARTAS, R. L. Fatores que influenciaram a implantação e desenvolvimento da agroindústria sob a ótica de Afred Weber: ocaso do oeste catarinense. Cadernos de Economia, Chapecó, v. 19, n. 35, p. 47-64, jan./jun. 2015.
LOPES, R. L.; CAIXETA FILHO, J. V. Suinocultura no Estado de Goiás: aplicação de um modelo de localização. Pesquisa Operacional, v. 20, n. 2, 2000. Disponível em: <http://www.scielo.br/pdf/pope/ v20n2/11235.pdf>. Acesso em: 24 dez. 2017.

MILHEIRA, R. G. Arqueologia Guarani no litoral sul-catarinense: história e território. 2010. Tese (Doutorado em Arqueologia) - Programa de PósGraduação em Arqueologia, Universidade de São Paulo, São Paulo, 2010.

NICOLDI, M. Evolução da noção da fertilidade e sua percepção como uma propriedade emergente do solo. 2007. Tese (Doutorado em ciências do Solo) - Programa de Pós-Graduação em Ciências do Solo, Universidade Federal do Rio Grande do Sul, Porto Alegre. 2007.

NOELLI, F. S. A ocupação humana na Região Sul do Brasil: arqueologia, debates e perspectivas 198722000. Revista USP, São Paulo, n. 44, p. 218-269, dez./fev. 1999-2000.

PERTILE, N. O capital agroindustrial catarinense e o Estado. GeoTextos, v. 17, n. 1, p. 13-30, jul. 2011.

PESSOA, M, V.; RIGOTTO, R. M.; Agronegócio: geração de desigualdades sociais, impactos no modo de vida e novas necessidades de saúde nos trabalhadores rurais. Revista Brasileira de Saúde Ocupacional, São Paulo, v. 37, jun. 2012.

PLEIN, C. A formação da agricultura familiar no Oeste de Santa Catarina: o caso das colônias Porto Feliz e Porto Novo. Revista Faz Ciência, v. 7, n. 1, p. 79-102, 2005.

POLI, J. Caboclo: pioneirismo e marginalização. Cadernos do CEOM, Chapecó, v. 10, n. 1-8, p. 71110, 1995.

RECHE, D.; SUGAI, M. I. A influência do capital agroindustrial na distribuição socioespacial urbana do município de Chapecó no sul do Brasil. In: COLOQUIO INTERNACIONAL DE GEOCRÍTICA, Barcelona, 10. Anais... Universidad de Barcelona, 26-30 de mayo de 2008. Disponível 
em: <http://www.ub.edu/geocrit/-xcol/257.htm>. Acesso em: 24 dez. 2017.

SCHMITZ, P. I.; FERRASSO, S. Caça, pesca e coleta de uma aldeia guarani. In: CARBONERA, M.; SCHMITZ. P. I. (Orgs.). Antes do este catarinense: arqueologia dos povos indígenas. Chapecó: Argos, 2011, p. 139-166.

SILVA, C. M. "Uma contribuição para sua comunidade e da Pátria": juventude rural e Clubes 4-S durante a ditadura militar no Oeste de Santa Catarina (1970-1985). Cadernos do CEOM, Chapecó, v. 23, n. 33, p. 37-66, 2010.

SILVESTRO, M. L. As transformações da agricultura família e estratégias de reprodução: o caso do Oeste. 1995. Dissertação (Mestrado em Ciências Sociais e Desenvolvimento Agricultura e Sociedade) - Universidade Federal Rural do rio de Janeiro, Rio de Janeiro, 1995.

SILVESTRO, M. L. et al. Os impasses sociais da sucessão hereditária na agricultura familiar. Florianópolis: EPAGRI; Brasília: NEAD/MDA, 2001.
SPANEVELLO, R. M. A dinâmica sucessória na agricultura familiar. 2008. Tese (Doutor em Desenvolvimento Rural) - Programa de PósGraduação em Desenvolvimento Rural, UFRGS, Rio Grande do Sul. 2008.

STROPASOLAS, V. L. Os desafios da sucessão geracional na agricultura familiar. Agriculturas, v. 8, n. 1, 2011.

WOLOSZYN, N. Em busca da terra: colonização e exploração de madeiras no oeste catarinense. Mimeo. 2005. Disponível em: <http://www. portouniaodavitoria.com.br/contestado/embusca-da-terra-coloniza\%C3\%A7\%C3\%A3o-eexplora\%C3\%A7\%C3\%A3o-de-madeiras-nooeste-catarinense/>. Acesso em: 30 nov. 2016.

WERLANG, A. A. Processo de colonização no oeste de Santa Catarina: atuação da Cia. Territorial Sul Brasil. Cadernos do CEOM, Chapecó, ano 9, n. 9, p. 9-46, jul. 1995. 